\title{
Article \\ Aqueous Two-Phase Extraction, Antioxidant and Renal Protective Effects of Polysaccharides from Spores of Cordyceps cicadae
}

\author{
Yi Zheng *, Shiying Li, Chuang Li, Ying Shao and Anhui Chen *
}

check for updates

Citation: Zheng, Y.; Li, S.; Li, C.; Shao, Y.; Chen, A. Aqueous Two-Phase Extraction, Antioxidant and Renal Protective Effects of Polysaccharides from Spores of Cordyceps cicadae. Processes 2022, 10, 348. https://doi.org/ $10.3390 /$ pr10020348

Received: 4 January 2022

Accepted: 10 February 2022

Published: 11 February 2022

Publisher's Note: MDPI stays neutral with regard to jurisdictional claims in published maps and institutional affiliations.

Copyright: (C) 2022 by the authors. Licensee MDPI, Basel, Switzerland. This article is an open access article distributed under the terms and conditions of the Creative Commons Attribution (CC BY) license (https:// creativecommons.org/licenses/by/ $4.0 /)$
School of Food and Biological Engineering, Xuzhou University of Technology, Xuzhou 221018, China; 1sy842426@163.com (S.L.); a1484262436@163.com (C.L.); shyzhbo2005@126.com (Y.S.)

* Correspondence: yizheng@xzit.edu.cn (Y.Z.); chenah201@163.com (A.C.)

\begin{abstract}
The aim of this study was to investigate the aqueous two-phase extraction (ATPE), in vitro antioxidant, and in vivo renal protective effects of polysaccharides from spores of Cordyceps cicadae (CCSPs). The optimal ATPE parameters were as follows: an extraction temperature of $61{ }^{\circ} \mathrm{C}$, an ammonium sulfate concentration of $18 \%$, an ethanol concentration of $40 \%$, a liquid-to-material ratio of $33 \mathrm{~mL} / \mathrm{g}$, and an extraction time of $60 \mathrm{~min}$. Under these parameters, the CCSPs yield was $6.96 \pm 0.11 \%(n=3)$, which was consistent with the predicted yield (6.92\%). Among the three purified polysaccharide fractions, CCSP-2 displayed stronger scavenging activities against DPPH radicals and hydroxyl radicals, reducing power and ferrous-ion-chelating ability to a greater extent than CCSP-1 and CCSP-3. CCSP-2 exhibited its protective effect in lipopolysaccharide (LPS)-induced septic acute kidney injury (AKI) mice by significantly alleviating renal edema; reducing $24 \mathrm{~h}$ urine protein, blood urea nitrogen (BUN), and serum creatinine (SCr); inhibiting the release of serum proinflammatory cytokines; boosting the activities of antioxidant enzymes; and reducing the levels of oxidative damage products. These results suggest that CCSP-2 exerted its protective effect against LPS-induced septic AKI in mice through anti-inflammatory and antioxidant pathways.
\end{abstract}

Keywords: polysaccharide; Cordyceps cicadae; spore; aqueous two-phase extraction; antioxidant; renal protective

\section{Introduction}

Cordyceps cicadae is a well-known traditional edible and medicinal fungus. It possesses chemical constituents and pharmacological effects similar to C. sinensis and C. militaris, and is expected to be an alternative source of Cordyceps [1-3]. Polysaccharides are the most attractive bioactive compounds derived from $C$. cicadae. In recent years, researchers have shown an increased interest in polysaccharides from $C$. cicadae due to their broad pharmacological activities, including their antioxidant [4], anti-inflammatory [5], immunomodulatory [6,7], antidiabetic [8], antibacterial [9], neuroprotective [10], and nephroprotective [11] activities However, earlier research has focused almost exclusively on polysaccharides derived from the coremium and mycelium rather than from spores; it is assumed that the pharmaceutical activity of the spores might be higher than those of the mycelium and coremium [12]. Nevertheless, polysaccharides from the spores of $C$. cicadae (CCSPs) have hitherto been poorly investigated, partly due to the difficulties associated with their collection.

Hot water extraction (HWE) is a traditional method for the extraction of polysaccharides, which has some disadvantages, such as having a low yield and being solventconsuming, energy-consuming, and time-consuming. Green extraction is an inevitable trend in natural polysaccharide research; a variety of novel extraction technologies have been developed, including microwave-assisted extraction, supercritical fluid extraction, and ultrasonic-assisted extraction. However, these methods require expensive equipment and are difficult to apply to industrial production [13]. As another novel green extraction 
technology, aqueous two-phase extraction (ATPE) technology has the following advantages: (1) the water content of the aqueous two-phase system (ATPS) is very high (70-90\%), and it can be performed in close-to-physiological conditions that make it difficult to cause the inactivation or denaturation of biological substances; (2) the phase separation time is short, the mass transfer is fast, the recovery rate is high, and the energy consumption is low; (3) various impurities can be removed during the extraction process, making the entire separation process more economical; (4) it is easy to scale-up, which is particularly advantageous for industrial applications; and (5) it is easy to operate continuously, and the equipment is simple. Generally, an ATPS can be formed with polymer-polymer, polymerinorganic salt, low-molecular-weight alcohol-inorganic salt, surfactant-surfactant, or ionic liquid-inorganic salt aqueous solutions [14]. Among them, the alcohol-salt ATPS provides the additional advantage of being relatively cheap and having low viscosity as well as easy solvent recovery. It has been widely used in the extraction of natural products such as polysaccharides [15-18] and phenolic compounds [19-21]. To the best of our knowledge, there is no report on the extraction of CCSPs via the ATPE technique.

Sepsis is a systemic inflammatory response syndrome induced by microorganisms or other pathogens. Acute kidney injury (AKI) is one of the most common sepsis-associated organ dysfunctions. It is reported that septic AKI accounts for 30-50\% of all septic patients [22]. Septic AKI is characterized by a higher rate of mortality and morbidity compared with non-septic AKI. In addition, some septic AKI patients progress to chronic kidney disease (CKD). Currently, the pathogenesis of septic AKI has not been completely elucidated, but it is recognized that oxidative stress, inflammatory responses, and immune responses are involved. In recent years, natural polysaccharides have attracted widespread attention due to their anti-inflammatory, antioxidant, immunomodulatory, and antitumor effects. A large number of studies have shown that natural polysaccharides can effectively improve sepsis-associated organ damage, such as kidney [23], lung [24], and cardiac [25] damage. Studies have also found that natural polysaccharides can improve numerous types of kidney diseases, including diabetic nephropathy [26,27], drug-related kidney injury [28,29], and renal ischemia-reperfusion injury [30]. Polysaccharides from Sanguisorba officinalis [31], Lycium barbarum [23], Echinacea [32], and Astragalus [33] have been reported to alleviate sepsis AKI via the suppression of oxidative stress and inflammatory responses. It has been demonstrated that $C$. cicadae and its extracts exert a protective role in kidney diseases. Huang et al. reported that C. cicadae offered a protective effect on tubular epithelial cells under hypertensive conditions [34]. Deng et al. reported that a water extract of C. cicadae could ameliorate cisplatin-induced kidney injury via the inhibition of oxidative stress and inflammation [35]. However, the components responsible for the nephroprotective effect have not been distinctly determined. These results provide a basis for evaluating the ameliorative effects of CCSPs on septic AKI.

The main aim of this study is to optimize the ATPE parameters of CCSPs via a BoxBehnken design and investigate its antioxidant ability as well as renal protective effect on lipopolysaccharide (LPS)-induced septic AKI mice.

\section{Materials and Methods}

\subsection{Materials and Chemicals}

Spores of C. cicadae were cultivated and collected from Jiangsu Key Construction Laboratory of Food Resource Development and Quality Safe. DEAE-cellulose (DE-52), Sephadex G-100, and LPS were purchased from Sigma (St. Louis, MO, USA). TNF- $\alpha$, IL-1 $\beta$, and IL-6 kits were supplied by R\&D Systems (Minneapolis, MN, USA). Blood urea nitrogen $(B U N)$, catalase (CAT), glutathione peroxidase (GSH-Px), malondialdehyde (MDA), protein carbonyl group (PCG), serum creatinine (SCr), total superoxide dismutase (T-SOD), and urine protein quantitative kits were acquired from Jiancheng Bioengineering Institute (Nanjing, China). 


\subsection{ATPE of Polysaccharides}

\subsubsection{Phase Diagram of ATPS}

Turbidimetric titration was employed to draw the phase diagram of an ATPS. Anhydrous ethanol was added to $60 \%$ ammonium sulfate solution and stirred continuously during the dripping process. When the solution became turbid, the amount of ethanol was recorded, and then a certain amount of distilled water was added until the turbidity disappeared. The above steps were repeated. The ethanol concentration and ammonium sulfate concentration at each cloud point were calculated, and the phase diagram was drawn.

\subsubsection{ATPE Process}

The spores of $C$. cicadae were first degreased with petroleum ether and then pretreated with $95 \%$ ethanol twice. The precipitates were then collected by centrifugation $(3500 \mathrm{r} / \mathrm{min}$ for $10 \mathrm{~min}$ ) and dried to a constant weight. A certain concentration of ethanol and ammonium sulfate solution was added to prepare an ethanol-ammonium sulfate ATPS. After the formation of the ATPS, $1 \mathrm{~g}$ of $C$. cicadae spore powder was added and extracted for a certain time at a certain temperature. After the ATPE the upper phase was collected to recover ethanol via rotary evaporation. The lower phase was recovered, concentrated, and precipitated in ethanol (final concentration of $80 \%$ ) at $4{ }^{\circ} \mathrm{C}$ for $12 \mathrm{~h}$, centrifuged at $3000 \mathrm{r} / \mathrm{min}$ for $10 \mathrm{~min}$, and the precipitate was collected. The precipitate was washed with 95\% ethanol 3 times, dialyzed (molecular weight cutoff: $4000 \mathrm{Da}$ ) with distilled water for $48 \mathrm{~h}$, concentrated, and freeze-dried to obtain CCSPs. The phenol-sulfuric acid method was used to determine the yield of polysaccharides [36]. The polysaccharide yield (\%) was estimated as follows:

Polysaccharides yield $(\%)=$ weight of polysaccharides $/$ weight of sample $\times 100$

\subsubsection{Single-Factor Test}

A single-factor test was conducted to investigate the effects of ammonium sulfate concentration $(12 \%, 14 \%, 16 \%, 18 \%$, and $20 \%)$, ethanol concentration $(35 \%, 40 \%, 45 \%, 50 \%$, and $55 \%$ ), liquid-to-material ratio $(15,20,25,30$, and $35 \mathrm{~mL} / \mathrm{g})$, extraction temperature $\left(30,40,50,60\right.$, and $\left.70{ }^{\circ} \mathrm{C}\right)$, and extraction time $(20,40,60,80$, and $100 \mathrm{~min})$ on the yield of CCSPs.

\subsubsection{Box-Behnken Design}

Based on the single-factor test a Box-Behnken design was adopted to arrange the four-factor and three-level test. The test factors and levels are shown in Table 1.

Table 1. Factors and levels of the Box-Behnken design.

\begin{tabular}{lllll}
\hline \multirow{2}{*}{ Independent Variables } & Symbol & \multicolumn{3}{c}{ Levels } \\
\cline { 3 - 5 } & & $\mathbf{- 1}$ & $\mathbf{0}$ & $\mathbf{1}$ \\
\hline Extraction temperature $\left({ }^{\circ} \mathrm{C}\right)$ & $\mathrm{A}$ & 50 & 60 & 70 \\
Ammonium sulfate concentration $(\%)$ & $\mathrm{B}$ & 16 & 18 & 20 \\
Ethanol concentration $(\%)$ & $\mathrm{C}$ & 35 & 40 & 45 \\
Liquid-to-material ratio $(\mathrm{mL} / \mathrm{g})$ & $\mathrm{D}$ & 25 & 30 & 35 \\
\hline
\end{tabular}

\subsection{Hot Water Extraction}

CCSPs were prepared by hot water extraction (HWE) as a control experiment. The HWE parameters were as follows: an extraction temperature of $95{ }^{\circ} \mathrm{C}$, an extraction time of $3 \mathrm{~h}$, and a liquid-to-material ratio of $30 \mathrm{~mL} / \mathrm{g}$. The contents of carbohydrate, protein, and total phenols in the products prepared by ATPE and HWE were determined by the phenol-sulfuric acid method, Bradford method, and Folin phenol method, respectively. 


\subsection{Purification of Polysaccharides}

The crude CCSPs were purified using the previously reported method [37]. Briefly, the crude CCSPs $(20 \mathrm{~g} / \mathrm{L})$ were sampled to a DE-52 cellulose column $(2.6 \mathrm{~cm} \times 30 \mathrm{~cm})$ and eluted step-wise with different concentrations of sodium chloride $(0,0.1,0.3$, and $0.5 \mathrm{~mol} / \mathrm{L})$ at a flow rate of $1 \mathrm{~mL} / \mathrm{min}$. Consequently, three fractions were obtained, concentrated, dialyzed, and further purified by a Sephadex G-100 column $(2.6 \mathrm{~cm} \times 60 \mathrm{~cm})$ eluted with deionized water at a flow rate of $0.5 \mathrm{~mL} / \mathrm{min}$ to afford CCSP-1, CCSP-2, and CCSP-3, respectively.

\subsection{In Vitro Antioxidant Activity Assays}

\subsubsection{DPPH Radical Scavenging Ability}

The DPPH radical scavenging ability of purified polysaccharide fractions was determined by a previously reported method [38] with some modifications. Of a polysaccharide solution $(0.1-4 \mathrm{~g} / \mathrm{L}), 1.5 \mathrm{~mL}$ was mixed with $1.5 \mathrm{~mL}$ of a DPPH solution $(0.2 \mathrm{mmol} / \mathrm{L})$, stood in the dark for $0.5 \mathrm{~h}$ at room temperature, and the absorbance at $517 \mathrm{~nm}$ was determined. Ascorbic acid (0.05-4 g/L) was used as a positive control. The DPPH radical scavenging rate of the polysaccharide samples was measured in accordance with the following formula:

$$
\text { Scavenging rate }(\%)=\left[1-\left(A_{2}-A_{3}\right) A_{1}\right] \times 100
$$

where $A_{1}$ is the absorbance of $1.5 \mathrm{~mL}$ of distilled water mixed with $1.5 \mathrm{~mL}$ of $0.2 \mathrm{mmol} / \mathrm{L}$ DPPH solution, $A_{2}$ is the absorbance of $1.5 \mathrm{~mL}$ of polysaccharide solution mixed with $1.5 \mathrm{~mL}$ of $0.2 \mathrm{mmol} / \mathrm{L} \mathrm{DPPH}$ solution, and $A_{3}$ is the absorbance of $1.5 \mathrm{~mL}$ of polysaccharide solution mixed with $1.5 \mathrm{~mL}$ of $95 \%$ ethanol.

\subsubsection{Hydroxyl Radical Scavenging Ability}

Hydroxyl radical scavenging ability was detected by o-phenanthroline spectrophotometry [39]. The concentrations of polysaccharides were $0.1-6 \mathrm{~g} / \mathrm{L}$, ascorbic acid $(0.1-6 \mathrm{~g} / \mathrm{L})$ was used as a positive control, and absorbance at $536 \mathrm{~nm}$ was detected. The test groups were as follows:

Damaged group: $0.5 \mathrm{~mL}$ of o-phenanthroline ethanol solution $(0.75 \mathrm{mmol} / \mathrm{L})$ was mixed with $1 \mathrm{~mL}$ of phosphate buffer $(0.15 \mathrm{mmol} / \mathrm{L}, \mathrm{pH} 7.4)$ and $0.5 \mathrm{~mL}$ of deionized water. Then, $0.5 \mathrm{~mL}$ of $0.75 \mathrm{mmol} / \mathrm{L} \mathrm{FeSO}_{4}$ and $0.5 \mathrm{~mL}$ of $0.01 \% \mathrm{H}_{2} \mathrm{O}_{2}$ were added into the mixture and incubated at $37^{\circ} \mathrm{C}$ for $1 \mathrm{~h}$. The measured absorbance was denoted as $A_{\mathrm{d}}$. Undamaged group: $0.5 \mathrm{~mL}$ of $0.01 \% \mathrm{H}_{2} \mathrm{O}_{2}$ was replaced with $0.5 \mathrm{~mL}$ of deionized water. Other procedures were the same as for the damaged group, and the measured absorbance was marked as $A_{\mathrm{u}}$. Sample group: $0.5 \mathrm{~mL}$ of deionized water was replaced with $0.5 \mathrm{~mL}$ of sample solution. Other procedures were the same as the damaged group, and the measured absorbance was denoted as $A_{\mathrm{s}}$. Sample reference group: $0.5 \mathrm{~mL}$ of o-phenanthroline ethanol solution was replaced with $0.5 \mathrm{~mL}$ of deionized water. The other procedures were the same as the sample group, and the measured absorbance was marked as $A_{\mathrm{r}}$. Blank reference group: $0.5 \mathrm{~mL}$ of sample solution was replaced with $0.5 \mathrm{~mL}$ of deionized water. The other procedures were the same as the sample reference group, and the measured absorbance was marked as $A_{\mathrm{b}}$.

The hydroxyl radical scavenging rate of polysaccharide samples was measured in accordance with the following formula:

$$
\text { Scavenging rate }(\%)=\left[\left(A_{\mathrm{s}}-A_{\mathrm{r}}\right)-\left(A_{\mathrm{d}}-A_{\mathrm{b}}\right) /\left(A_{\mathrm{u}}-A_{\mathrm{d}}\right)\right] \times 100
$$

where $A_{\mathrm{b}}, A_{\mathrm{d}}, A_{\mathrm{r}}, A_{\mathrm{s}}$, and $A_{\mathrm{u}}$ are the absorbances of the blank reference group, damaged group, sample reference group, sample group, and undamaged group, respectively.

\subsubsection{Reducing Power}

The reducing power was detected using the potassium ferricyanide method reported by Oraiza [40]. Two milliliters of sample solution $(0.05-4 \mathrm{~g} / \mathrm{L})$ was mixed with $2 \mathrm{~mL}$ 
of phosphate-buffered solution $(0.2 \mathrm{~mol} / \mathrm{L}, \mathrm{pH} 6.6)$ and $2 \mathrm{~mL}$ of $1 \%$ potassium ferricyanide solution. The mixture was incubated at $50{ }^{\circ} \mathrm{C}$ for $20 \mathrm{~min}$, mixed with $2 \mathrm{~mL}$ of $10 \%$ trichloroacetic acid solution, and centrifuged at $3000 \mathrm{r} / \mathrm{min}$ for $10 \mathrm{~min}$. After centrifugation, $2 \mathrm{~mL}$ of supernatant was mixed with $2 \mathrm{~mL}$ of deionized water and $0.4 \mathrm{~mL}$ of $0.1 \%$ ferric chloride, incubated at $50{ }^{\circ} \mathrm{C}$ for $10 \mathrm{~min}$, and the absorbance was determined at $700 \mathrm{~nm}$. The sample was replaced with the same volume of deionized water in the blank group. Ascorbic acid (0.01-1 g/L) was used as a positive control.

\subsubsection{Chelating Ability against Ferrous Ions}

Chelating ability against ferrous ions was detected in the same manner as in the previous report [41]. One milliliter of sample solution $(0.05-4 \mathrm{~g} / \mathrm{L})$ was mixed with $3.7 \mathrm{~mL}$ of $55 \%$ ethanol, $0.1 \mathrm{~mL}$ of ferrous chloride $(2 \mathrm{mmol} / \mathrm{L})$, and $0.2 \mathrm{~mL}$ of ferrozine $(5 \mathrm{mmol} / \mathrm{L})$, and stood for $20 \mathrm{~min}$ to determine the absorbance at $562 \mathrm{~nm}$. The sample was replaced with the same volume of $55 \%$ ethanol in the blank control. EDTA $(0.05-4 \mathrm{~g} / \mathrm{L})$ was used as a positive control. The chelating rate against ferrous ions was measured as follows:

$$
\text { Chelating rate }(\%)=\left(A_{\mathrm{b}}-A_{\mathrm{s}}\right) A_{\mathrm{b}} \times 100
$$

where $A_{\mathrm{b}}$ and $A_{\mathrm{s}}$ are the absorbances of the blank control and the sample, respectively.

\subsection{Renal Protective Effect of CCSP-2}

\subsubsection{Animal Treatment}

Male Kunming mice (18-22 g) were supplied by Jinan Pengyue Laboratory Animal Breeding Co., Ltd. (production license No. SCXY (Lu) 20190003, Jinan, China). All mice were acclimatized for a week at a temperature of $22 \pm 2{ }^{\circ} \mathrm{C}$ and a relative humidity of $45-60 \%$. All experiments were in light of the NIH Guide for Care and Use of Laboratory Animals and were approved by the Institutional Animal Care and Use Committee.

The mice were randomly divided into five groups (eight mice in each group): control group, LPS group, and three CCSP-2-treated groups. The mice were intraperitoneally injected with $5 \mathrm{mg} / \mathrm{kg}$ LPS once a day for 3 consecutive days, except for the control group. Then, the mice in the low-, medium-, and high-dose CCSP-2-treated groups were intragastrically administered with 50,100 , and $200 \mathrm{mg} / \mathrm{kg}$ CCSP-2, respectively, once a day for three consecutive weeks. The doses of CCSP-2 selected were based on pre-experiment (data not shown) and previous studies [31,42]. The control group and LPS group mice were given normal saline.

After the last gavage, the mice were housed in metabolic cages for $24 \mathrm{~h}$ urine collection. Twenty-four-hour urine protein was determined by the quantitative kit. The mice were weighed and sacrificed after $24 \mathrm{~h}$ urine collection, then the kidney was removed.

\subsubsection{Determination of Wet Weight/Dry Weight Ratio of Kidney Tissue}

The right kidney tissue was removed, the surface water was dried with filter paper, and the kidney tissue was weighed, which is the wet weight. Then, the kidney tissue was placed in an oven at $60{ }^{\circ} \mathrm{C}$, dried to a constant weight, and weighed again, which is the dry weight. The wet weight/dry weight ratio of the kidney tissue was calculated by dividing the wet weight by the dry weight [43].

\subsubsection{Determination of Serum Biochemical Indicators and Cytokines}

Blood samples were collected from the retro-orbital venous plexus, centrifuged at $3000 \mathrm{r} / \mathrm{min}$ for $15 \mathrm{~min}$ at $4{ }^{\circ} \mathrm{C}$, and the serum was collected. The levels of BUN, SCr, TNF- $\alpha$, IL- $1 \beta$, and IL- 6 were determined according to the kit instructions.

\subsubsection{Determination of Antioxidase and Oxidative Damage Product Levels in Kidney Tissue}

The left kidney tissue was removed, cut into pieces, added to precooled normal saline, homogenized in an ice bath, and centrifuged at $3500 \mathrm{r} / \mathrm{min}$ at $4{ }^{\circ} \mathrm{C}$ for $15 \mathrm{~min}$; the 
supernatant was then collected. The levels of CAT, GSH-Px, T-SOD, MDA, and PCG in the kidney tissues were measured in accordance with the kit instructions.

\subsection{Statistical Analysis}

The results are expressed as mean \pm SD. The statistical significance between test groups and the control group was analyzed by one-way analysis of variance (ANOVA) with the Duncan method. $p<0.05$ and $p<0.01$ denote significant difference and highly significant difference, respectively.

\section{Results}

\subsection{Phase Diagram of ATPS}

The phase diagram of ethanol-ammonium sulfate ATPS was drawn using turbidimetric titration, as shown in Figure 1a. The upper phase was rich in ethanol, while the lower phase was rich in ammonium sulfate. In the ethanol-ammonium sulfate ATPS, the CCSPs were mainly distributed in the lower phase. In order to form the ATPS, the upper limit of the ammonium sulfate and ethanol concentrations was about $40 \%$ and $55 \%$, respectively.
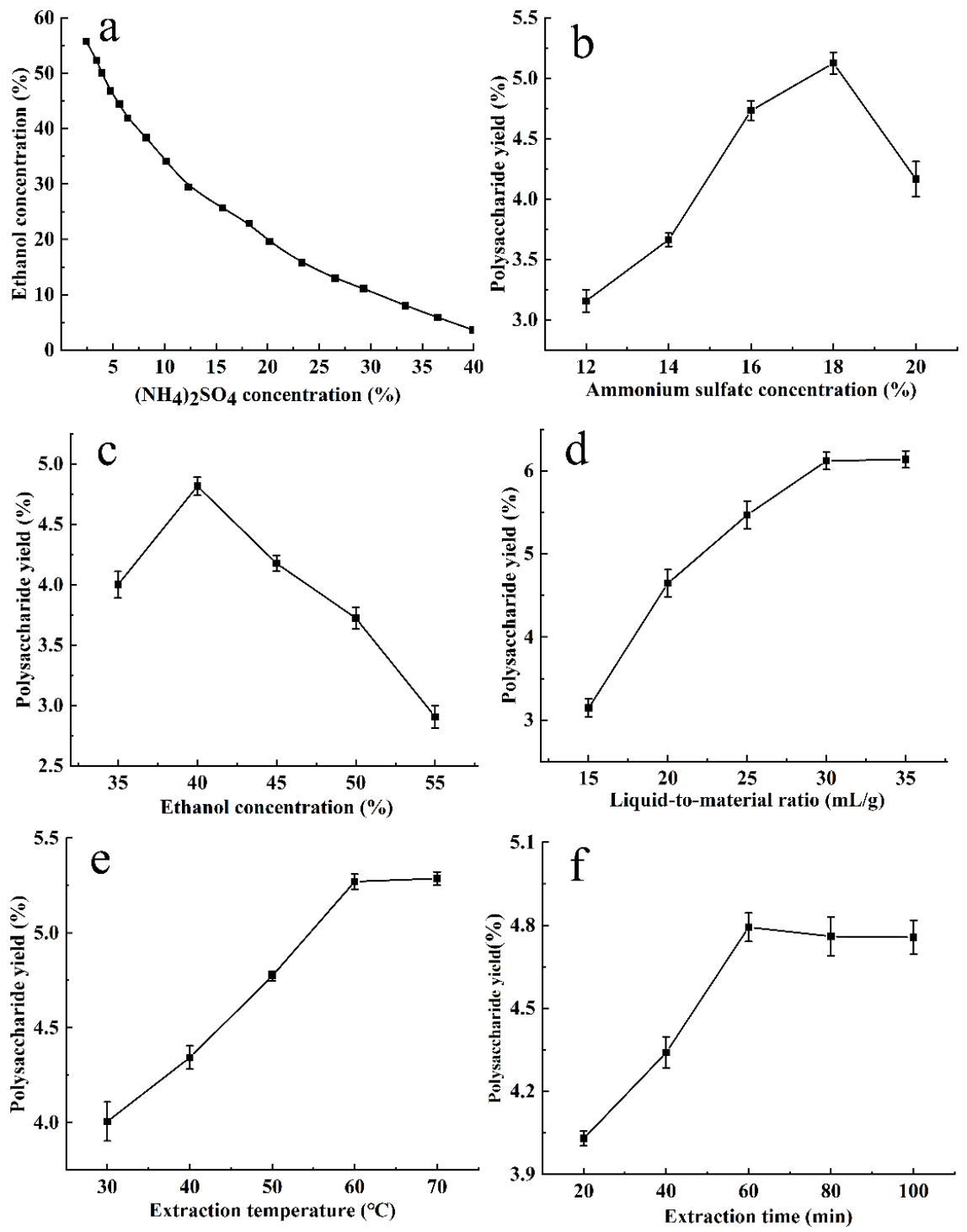

Figure 1. Phase diagram of ethanol-ammonium sulfate ATPS (a) and the effects of ammonium sulfate concentration (b), ethanol concentration (c), liquid-to-material ratio (d), extraction temperature (e), and extraction time (f) on the yield of CCSPs. Results are represented as mean $\pm \operatorname{SD}(n=3)$. 


\subsection{Single-Factor Test}

\subsubsection{Effect of Ammonium Sulfate Concentration on the Yield of CCSPs}

Figure $1 b$ exhibits the effect of the ammonium sulfate concentration on the yield of CCSPs. The other parameters were fixed as follows: an extraction time of $60 \mathrm{~min}$, an extraction temperature of $50{ }^{\circ} \mathrm{C}$, an ethanol concentration of $40 \%$, and a liquid-to-material ratio of $20 \mathrm{~mL} / \mathrm{g}$. The CCSPs yield increased with an increase in ammonium sulfate concentration below $18 \%$ and decreased when the ammonium sulfate concentration was higher than $18 \%$. When the ammonium sulfate concentration increased, the CCSP yield first increased and then decreased, which may be due to the synergistic effect of the partition coefficient and phase ratio. As the ammonium sulfate concentration increased, the volume of the lower phase increased, so more CCSPs were distributed to the lower phase. When the ammonium sulfate concentration was too high, the salting-out effect was enhanced; thus, the CCSPs yield decreased. In addition, it would cause a waste of ammonium sulfate and increase production costs. The ammonium sulfate concentration of $18 \%$ was initially selected as the optimal parameter for further experiments.

\subsubsection{Effect of Ethanol Concentration on the Yield of CCSPS}

The effect of the ethanol concentration on the yield of CCSPs was determined with an extraction time of $60 \mathrm{~min}$, an extraction temperature of $50{ }^{\circ} \mathrm{C}$, an ammonium sulfate concentration of $16 \%$, and a liquid-to-material ratio of $20 \mathrm{~mL} / \mathrm{g}$. It can be seen from Figure 1c that when the ethanol concentration was $40 \%$, the CCSPs yield reached its peak. When the ethanol concentration was too low, the separation efficiency was limited; thus, the CCSPs yield was lower. When the ethanol concentration was greater than $40 \%$, the CCSPs yield decreased due to the smaller volume of the lower phase. Therefore, $40 \%$ was initially selected as the optimal ethanol concentration for further experiments.

\subsubsection{Effect of Liquid-to-Material Ratio on the Yield of CCSPs}

The effect of the liquid-to-material ratio on the yield of CCSPs is displayed in Figure 1d. The other parameters were fixed as follows: an extraction time of $60 \mathrm{~min}$, an extraction temperature of $50{ }^{\circ} \mathrm{C}$, an ammonium sulfate concentration of $16 \%$, and an ethanol concentration of $40 \%$. When the liquid-to-liquid ratio increased from 15 to $30 \mathrm{~mL} / \mathrm{g}$, the CCSPs yield increased sharply, and when the liquid-to-solid ratio exceeded $30 \mathrm{~mL} / \mathrm{g}$, the CCSPs yield increased gently. If the liquid-to-material ratio was too low, the polysaccharide could not be extracted completely, and if it was too high, it would increase the energy consumption of subsequent operations. The optimal liquid-to-material ratio was initially selected as $30 \mathrm{~mL} / \mathrm{g}$ for further experiments.

\subsubsection{Effect of Extraction Temperature on the Yield of CCSPs}

The effect of the extraction temperature on the yield of CCSPs was investigated with an extraction time of $60 \mathrm{~min}$, an ammonium sulfate concentration of $0.16 \%$, an ethanol concentration of $40 \%$, and a liquid-to-material ratio of $20 \mathrm{~mL} / \mathrm{g}$. As can be found in Figure 1e, when the extraction temperature rose from 30 to $60^{\circ} \mathrm{C}$, the CCSPs yield increased. The possible reason for this might be that the solubility of CCSPs in the lower phase increases with an increase in the extraction temperature. The CCSPs yield increased gently when the extraction temperature exceeded $60^{\circ} \mathrm{C}$. The optimal extraction temperature was initially selected as $60{ }^{\circ} \mathrm{C}$ for further experiments.

\subsubsection{Effect of Extraction Time on the Yield of CCSPS}

The effect of the extraction time on the yield of CCSPs was observed with an extraction temperature of $50{ }^{\circ} \mathrm{C}$, an ammonium sulfate concentration of $0.16 \%$, an ethanol concentration of $40 \%$, and a liquid-to-material ratio of $20 \mathrm{~mL} / \mathrm{g}$. As shown in Figure $1 \mathrm{f}$, the yield of CCSPs increased rapidly when the extraction time was in the range of 20-60 min, while the yield hardly increased when the extraction time exceeded $60 \mathrm{~min}$. Therefore, $60 \mathrm{~min}$ was selected as the optimal extraction time for further experiments. 
In summary, the optimal APTE parameters on the yield of CCSPs based on the singlefactor tests were as follows: an ammonium sulfate concentration of $18 \%$, an ethanol concentration of $40 \%$, a liquid-to-material ratio of $30 \mathrm{~mL} / \mathrm{g}$, an extraction temperature of $60{ }^{\circ} \mathrm{C}$, and an extraction time of $60 \mathrm{~min}$. Considering the degree of influence of various factors on the yield of CCSPs, the ammonium sulfate concentration, ethanol concentration, liquid-to-material ratio, and extraction temperature were selected for the Box-Behnken design experiment.

\subsection{Optimization of ATPE Process of CCSPS}

\subsubsection{Statistical Analysis and Model Fitting}

On the basis of the single-factor test, a Box-Behnken design was adopted to optimize the ATPE process of CCSPs. The results are shown in Table 2.

Table 2. The Box-Behnken design and the results for optimizing the ATPE process of CCSPs.

\begin{tabular}{|c|c|c|c|c|c|}
\hline Run & $\begin{array}{c}\text { Extraction } \\
\text { Temperature } \\
\left(A,{ }^{\circ} \mathrm{C}\right)\end{array}$ & $\begin{array}{c}\text { Ammonium } \\
\text { Sulfate } \\
\text { Concentration } \\
(B, \%)\end{array}$ & $\begin{array}{c}\text { Ethanol } \\
\text { Concentration } \\
(C, \%)\end{array}$ & $\begin{array}{c}\text { Liquid-to- } \\
\text { Material Ratio ( } D, \\
\mathrm{~mL} / \mathrm{g})\end{array}$ & $\begin{array}{l}\text { CCSPs } \\
\text { Yield } \\
(Y, \%)\end{array}$ \\
\hline 1 & 60 & 20 & 35 & 30 & 4.98 \\
\hline 2 & 60 & 18 & 40 & 30 & 6.85 \\
\hline 3 & 70 & 18 & 40 & 25 & 5.92 \\
\hline 4 & 60 & 20 & 40 & 25 & 5.19 \\
\hline 5 & 60 & 16 & 40 & 25 & 5.94 \\
\hline 6 & 60 & 18 & 40 & 30 & 6.75 \\
\hline 7 & 60 & 20 & 45 & 30 & 5.83 \\
\hline 8 & 60 & 18 & 35 & 35 & 6.31 \\
\hline 9 & 50 & 18 & 35 & 30 & 5.58 \\
\hline 10 & 50 & 16 & 40 & 30 & 5.97 \\
\hline 11 & 70 & 18 & 45 & 30 & 5.45 \\
\hline 12 & 70 & 20 & 40 & 30 & 5.63 \\
\hline 13 & 60 & 18 & 45 & 35 & 6.01 \\
\hline 14 & 60 & 18 & 40 & 30 & 6.72 \\
\hline 15 & 50 & 18 & 40 & 35 & 6.21 \\
\hline 16 & 70 & 16 & 40 & 30 & 6.18 \\
\hline 17 & 60 & 18 & 35 & 25 & 5.62 \\
\hline 18 & 60 & 20 & 40 & 35 & 5.69 \\
\hline 19 & 60 & 16 & 45 & 30 & 5.36 \\
\hline 20 & 60 & 18 & 45 & 25 & 5.19 \\
\hline 21 & 60 & 16 & 40 & 35 & 6.46 \\
\hline 22 & 50 & 20 & 40 & 30 & 5.13 \\
\hline 23 & 60 & 18 & 40 & 30 & 6.61 \\
\hline 24 & 70 & 18 & 40 & 35 & 6.47 \\
\hline 25 & 60 & 18 & 40 & 30 & 6.93 \\
\hline 26 & 50 & 18 & 40 & 25 & 5.65 \\
\hline 27 & 70 & 18 & 35 & 30 & 5.72 \\
\hline 28 & 50 & 18 & 45 & 30 & 5.23 \\
\hline 29 & 60 & 16 & 35 & 30 & 5.71 \\
\hline
\end{tabular}

The multiple nonlinear regression analysis of the data in Table 2 was conducted by using Design-Expert software, and the quadratic regression equation between the yield of CCSPs and the four factors was obtained as follows:

$$
\begin{aligned}
Y= & 6.77+0.13 A-0.26 B-0.071 C+0.30 D+0.072 A B+0.020 A C-0.0025 A D \\
& +0.30 B C-0.0050 B D+0.032 C D-0.47 A^{2}-0.60 B^{2}-0.74 C^{2}-0.28 D^{2}
\end{aligned}
$$

Analysis of variance (ANOVA) was performed on Equation (5), and the results are shown in Table 3. The $p$-value of the model was less than 0.0001 , the $p$-value of the lack-of-fit was not significant, the determination coefficient $R^{2}$ was 0.9265 , and the signal-to-noise ratio (Adeq Precision) was 11.947. It was suggested that the fit and credibility of the mode were very high; thus, the model could be employed to optimize the ATPE process of CCSPs. 
Table 3. Analysis of variance (ANOVA) for quadratic regression equation.

\begin{tabular}{|c|c|c|c|c|c|c|}
\hline Source & $\begin{array}{l}\text { Sum of } \\
\text { Squares }\end{array}$ & df & $\begin{array}{l}\text { Mean } \\
\text { Square }\end{array}$ & $F$-Value & Prob $>F$ & Significance \\
\hline Model & 8.0467 & 14 & 0.5748 & 12.5971 & $<0.0001$ & $* *$ \\
\hline A & 0.2133 & 1 & 0.2133 & 4.6756 & 0.0484 & $*$ \\
\hline$B$ & 0.8374 & 1 & 0.8374 & 18.3535 & 0.0008 & $* *$ \\
\hline C & 0.0602 & 1 & 0.0602 & 1.3196 & 0.2699 & \\
\hline$D$ & 1.1041 & 1 & 1.1041 & 24.1994 & 0.0002 & $* *$ \\
\hline$A B$ & 0.0210 & 1 & 0.0210 & 0.4608 & 0.5083 & \\
\hline$A C$ & 0.0016 & 1 & 0.0016 & 0.0351 & 0.8541 & \\
\hline$A D$ & $2.5 \times 10^{-5}$ & 1 & $2.5 \times 10^{-5}$ & 0.0005 & 0.9817 & \\
\hline$B C$ & 0.3600 & 1 & 0.3600 & 7.8901 & 0.0139 & * \\
\hline$B D$ & 0.0001 & 1 & 0.0001 & 0.0022 & 0.9633 & \\
\hline$C D$ & 0.0042 & 1 & 0.0042 & 0.0926 & 0.7654 & \\
\hline$A^{2}$ & 1.4313 & 1 & 1.4313 & 31.3708 & $<0.0001$ & $* *$ \\
\hline$B^{2}$ & 2.3625 & 1 & 2.3625 & 51.7781 & $<0.0001$ & $* *$ \\
\hline$C^{2}$ & 3.5376 & 1 & 3.5376 & 77.5341 & $<0.0001$ & $* *$ \\
\hline$D^{2}$ & 0.5076 & 1 & 0.5076 & 11.1258 & 0.0049 & $* *$ \\
\hline Residual & 0.6388 & 14 & 0.0456 & & & \\
\hline Lack-of-fit & 0.5783 & 10 & 0.0578 & 3.8247 & 0.1040 & NS \\
\hline Pure error & 0.0605 & 4 & 0.0151 & & & \\
\hline Cor total & 8.6855 & 28 & & & & \\
\hline
\end{tabular}

The coefficients of $B, D, A^{2}, B^{2}, C^{2}$, and $D^{2}$ were extremely significant $(p<0.01)$, while those of $A$ and $B C$ were significant $(p<0.05)$. Moreover, the coefficients of $C, A B, A C, A D$, $B D$, and $C D$ were not significant $(p>0.05)$.

\subsubsection{Interactive Effect Analysis}

The response surface can intuitively reflect the impact of the interactive effect of the two factors on the yield of the target product. The steeper the slope of the response surface, the greater the impact of the interactive effect on the yield of CCSPs. As can be seen from Table 3, the interactive effect of the ammonium sulfate concentration and ethanol concentration had a significant influence on the yield of CCSPs; thus, only this interactive effect was analyzed. Figure 2 shows the interactive effect of the ammonium sulfate concentration and ethanol concentration on the yield of CCSPs when the other variables were maintained at zero level. The yield of CCSPs increased when the ammonium sulfate concentration increased from $16 \%$ to $18 \%$, while the CCSPs yield tended to decrease with an increase in the ammonium sulfate concentration beyond $18 \%$. Meanwhile, the yield of CCSPs also increased with an increase in the ethanol concentration from $35 \%$ to $40 \%$, and the CCSPs yield decreased when the ethanol concentration was greater than $40 \%$. The maximum yield of CCSPs was obtained when the ammonium sulfate concentration and ethanol concentration were selected as about $18 \%$ and $40 \%$, respectively.

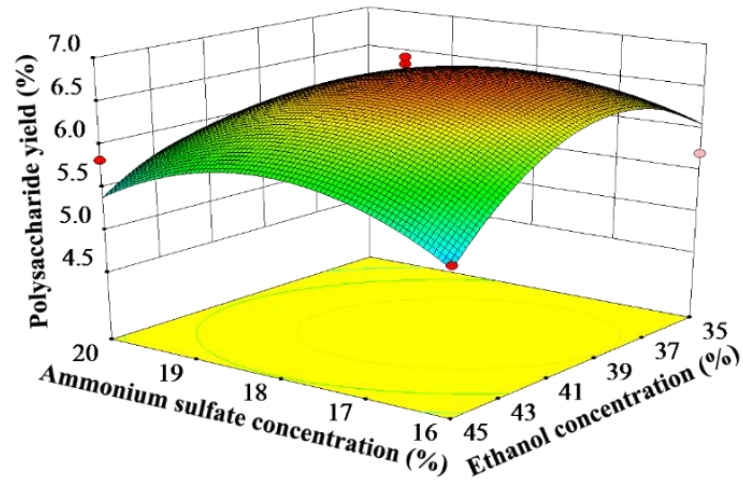

Figure 2. Response surface plots showing the interactive effect of ammonium sulfate concentration and ethanol concentration on the yield of CCSPs. 


\subsubsection{Verification of Predictive Model}

Based on Equation (5), the optimal ATPE parameters of CCSPs were as follows: an extraction temperature of $61{ }^{\circ} \mathrm{C}$, an ammonium sulfate concentration of $18 \%$, an ethanol concentration of $40 \%$, a liquid-to-material ratio of $33 \mathrm{~mL} / \mathrm{g}$, and an extraction time of $60 \mathrm{~min}$. Under these parameters, the CCSPs yield was $6.96 \pm 0.11 \%(n=3)$, which was in accordance with the predicted yield $(6.92 \%)$. Furthermore, a preliminary process scale-up experiment was performed as follows: $200 \mathrm{~g}$ of spores of $C$. cicadae was used to extract polysaccharides by ATPE, and the CCSPs yield was $6.94 \%$. These findings hinted that Equation (5) was valid for optimizing the ATPE process parameters of CCSPs.

\subsection{Comparison with HWE}

As can be seen from Table 4, compared with HWE, the ATPE method was characterized by a time-saving and high-yield potential that was more valid for the extraction of CCSPs. Interestingly, during the ATPE process, various impurities such as proteins and phenolic compounds can be enriched in the upper phase by optimizing the process parameters, and the extraction and preliminary purification can be performed simultaneously. Therefore, the purity of the CCSPs prepared by ATPE was superior to that of those produced by HWE.

Table 4. Comparison of polysaccharides prepared by ATPE and HWE.

\begin{tabular}{cccccc}
\hline $\begin{array}{c}\text { Extraction } \\
\text { Method }\end{array}$ & $\begin{array}{c}\text { Polysaccharide } \\
\text { Yield (\%) }\end{array}$ & $\begin{array}{c}\text { Extraction } \\
\text { Time (min) }\end{array}$ & $\begin{array}{c}\text { Carbohydrate } \\
\mathbf{( \% )}\end{array}$ & $\begin{array}{c}\text { Protein } \\
\text { (\%) }\end{array}$ & $\begin{array}{c}\text { Total } \\
\text { Phenols (\%) }\end{array}$ \\
\hline ATPE & $6.96 \pm 0.11$ & 60 & $86.15 \pm 4.34$ & $3.46 \pm 0.07$ & $1.05 \pm 0.04$ \\
HWE & $6.56 \pm 0.12$ & 180 & $61.27 \pm 3.72$ & $17.27 \pm 0.14$ & $4.62 \pm 0.08$ \\
\hline
\end{tabular}

Results are represented as means \pm SD $(n=3)$.

\subsection{Antioxidant Activities of Purified Polysaccharide Fractions}

\subsubsection{DPPH Radical Scavenging Ability}

The DPPH radical scavenging abilities of CCSP-1, CCSP-2, and CCSP-3 are presented in Figure 3a. Within the concentrations ranging from 0.05 to $4 \mathrm{~g} / \mathrm{L}$, the DPPH radical scavenging rates of the three fractions were positively correlated with the concentrations. At the concentration of $0.4 \mathrm{~g} / \mathrm{L}$, the scavenging rates of CCSP-1, CCSP-2, and CCSP-3 were $29.41 \pm 0.8 \%, 50.38 \pm 1.7 \%$, and $30.55 \pm 2.1 \%$, respectively; at the concentration of $3 \mathrm{~g} / \mathrm{L}$, the scavenging rates increased to $58.30 \pm 2.3 \%, 83.54 \pm 2.8 \%$, and $74.13 \pm 2.7 \%$, respectively. These results implied that CCSP-2 might be a more effective free radical scavenger than CCSP-1 and CCSP-3.

The half maximal effective concentration $\left(\mathrm{EC}_{50}\right)$ can be used as a crucial indicator for evaluating the antioxidant capacity. The smaller the $\mathrm{EC}_{50}$ value, the stronger the free radical scavenging capacity of the sample. The $\mathrm{EC}_{50}$ value is lower than $10 \mathrm{~g} / \mathrm{L}$, indicating that the tested sample has a certain antioxidant capacity. The EC $_{50}$ values of CCSP-1, CCSP-2, and CCSP-3 for DPPH radical scavenging ability, calculated by Origin 2018, were 1.02, 0.67 , and $0.35 \mathrm{~g} / \mathrm{L}$, respectively, which indicated that the three polysaccharide fractions had strong DPPH radical scavenging ability; the order of scavenging ability was CCSP-2 > CCSP-3 $>$ CCSP-1. The $\mathrm{EC}_{50}$ value of ascorbic acid for the DPPH radical scavenging ability was $0.12 \mathrm{~g} / \mathrm{L}$, suggesting that the scavenging ability of the three polysaccharide fractions was lower than that of ascorbic acid.

\subsubsection{Hydroxyl Radical Scavenging Assay}

As displayed in Figure 3b, the scavenging activities of CCSP-1, CCSP-2, and CCSP-3 against hydroxyl radicals were positively correlated with increasing concentrations. At a concentration of $3.0 \mathrm{~g} / \mathrm{L}$ the scavenging rates of CCSP-1, CCSP-2, and CCSP-3 against hydroxyl radicals were $61.33 \pm 2.4 \%, 69.74 \pm 2.3 \%$, and $58.95 \pm 3.2 \%$, respectively. Additionally, CCSP-1, CCSP-2, and CCSP-3 showed more potent scavenging activities against hydroxyl radicals than ascorbic acid. The $\mathrm{EC}_{50}$ values of CCSP-1, CCSP-2, CCSP-3, and 
ascorbic acid for hydroxyl radical scavenging activity were 1.71, 0.77, 1.76, and $1.62 \mathrm{~g} / \mathrm{L}$, respectively. On account of the $\mathrm{EC}_{50}$ values, the order of hydroxyl radical scavenging ability was CCSP-2 > CCSP-1 > CCSP-3 > ascorbic acid.
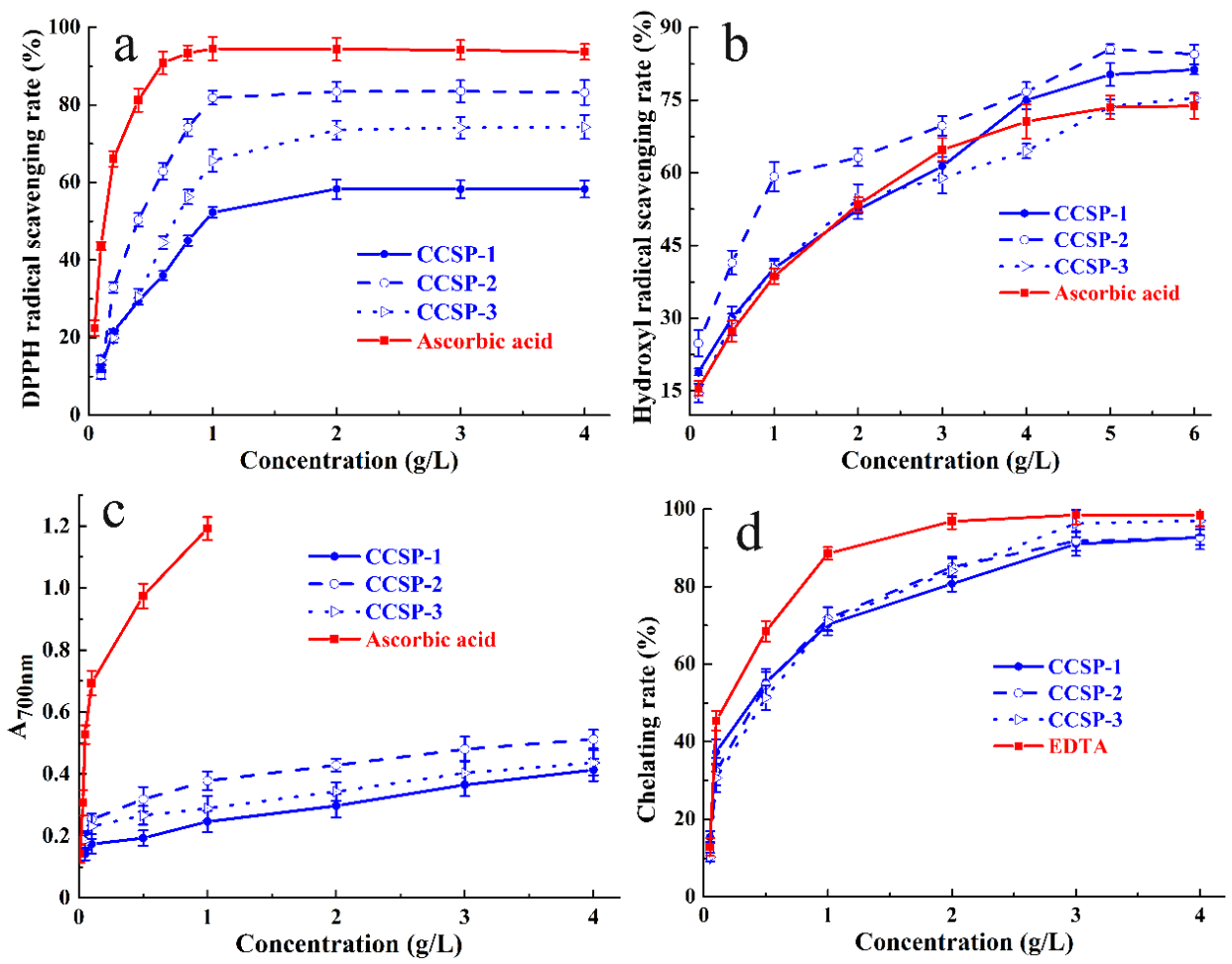

Figure 3. Antioxidant activities of CCSP-1, CCSP-2, and CCSP-3. (a) DPPH radical scavenging activity. (b) Hydroxyl radical scavenging ability determined by o-phenanthroline spectrophotometry. (c) Reducing power determined by potassium ferricyanide method. (d) Chelating ability against ferrous ions. Results are represented as means $\pm \mathrm{SD}(n=3)$.

\subsubsection{Reducing Power}

Figure $3 \mathrm{c}$ reveals the reducing power of CCSP-1, CCSP-2, and CCSP-3 determined by the potassium ferricyanide method. All the polysaccharide fractions exhibited concentrationdependent reducing power. At a concentration of $0.5 \mathrm{~g} / \mathrm{L}$, the reducing power of CCSP-1, CCSP-2, and CCSP-3 were $0.193 \pm 0.02,0.318 \pm 0.04$, and $0.266 \pm 0.03$, respectively. Additionally, at a concentration of $4 \mathrm{~g} / \mathrm{L}$, the reducing power increased to $0.413 \pm 0.04$, $0.512 \pm 0.03$, and $0.436 \pm 0.04$, respectively. CCSP-2 exhibited relatively higher reducing ability than that of CCSP-1 and CCSP-3. The reducing power of ascorbic acid was significantly higher than that of the polysaccharide fractions.

\subsubsection{Chelating Ability against Ferrous Ions}

Figure $3 \mathrm{~d}$ exhibits the chelating abilities of CCSP-1, CCSP-2, and CCSP-3 against ferrous ions. All the fractions exhibited concentration-dependent chelating abilities against ferrous ions. At a concentration of $0.5 \mathrm{~g} / \mathrm{L}$, the chelating rates of CCSP-1, CCSP-2, and CCSP-3 against ferrous ions were $55.32 \pm 3.4 \%, 54.67 \pm 3.3 \%$, and $51.36 \pm 3.1 \%$, respectively, whereas at $3.0 \mathrm{~g} / \mathrm{L}$, the chelating rates increased to $90.98 \pm 3.1 \%, 91.78 \pm 2.5 \%$, and $96.31 \pm 3.5 \%$, respectively. However, EDTA exhibited a stronger chelating rate of $96.86 \pm 2.1 \%$ at $2 \mathrm{~g} / \mathrm{L}$. The $\mathrm{EC}_{50}$ values of CCSP-1, CCSP-2, CCSP-3, and EDTA for chelating capacity against ferrous ions were $0.30,0.31,0.37$ and $0.14 \mathrm{~g} / \mathrm{L}$, respectively. According to the $\mathrm{EC}_{50}$ values, there was almost no difference among three polysaccharide fractions.

In summary, CCSP-1, CCSP-2, and CCSP-3 exhibited potent antioxidant activities in four different assays, including a DPPH radical scavenging assay, a hydroxyl radical scavenging assay, a reducing power assay, and a ferrous-ion-chelating assay. Considering 
that CCSP-2 had the strongest antioxidant capacity, it was chosen to further evaluate its in vivo renal protective effect.

\subsection{Renal Protective Effect of CCSP-2}

\subsubsection{Effect of CCSP-2 on Kidney Wet Weight/Dry Weight Ratio}

The wet weight/dry weight ratio of kidney tissues can reflect the renal edema in mice. Figure 4a displays the kidney wet weight/dry weight ratio of each group mice. Compared with the control group, the kidney wet weight/dry weight ratio in the LPS group increased significantly $(p<0.01)$, indicating that LPS caused a severe renal edema in the mice. Compared with the LPS group, the kidney wet weight/dry weight ratios in the low-, medium-, and high-dose CCSP-2 groups were significantly reduced $(p<0.01)$, indicating that CCSP-2 could alleviate the LPS-induced renal edema in mice. Additionally, the kidney wet weight/dry weight ratio in the high-dose CCSP-2 group was not significantly different from that of the control group.
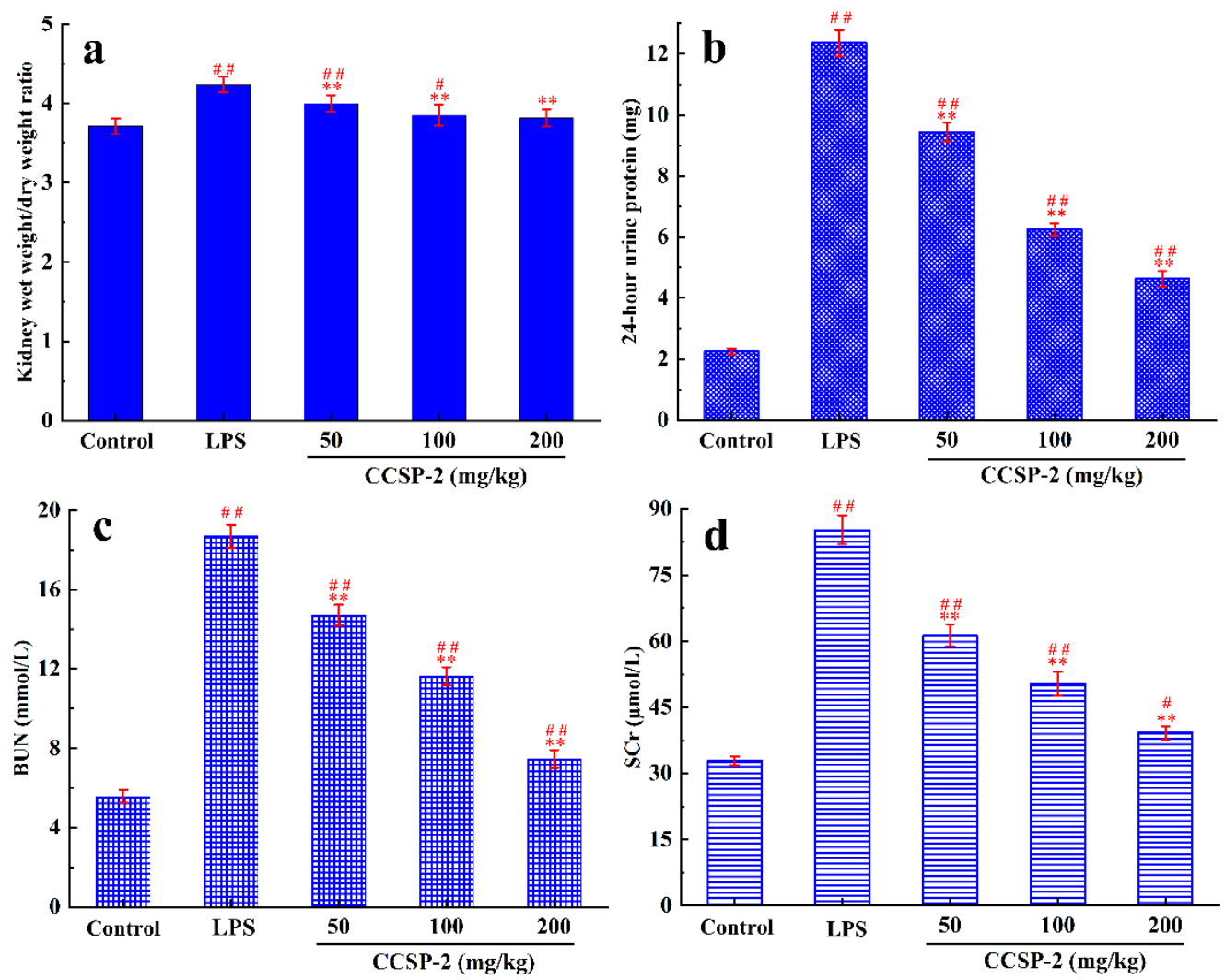

Figure 4. Effects of CCSP-2 on kidney wet weight/dry weight ratio (a), $24 \mathrm{~h}$ urine protein level (b), BUN level (c), and SCr level (d) in LPS-induced septic AKI mice. Data are represented as means $\pm \mathrm{SD}(n=8) .{ }^{* *} p<0.01$, by contrast with LPS group. ${ }^{\# \#} p<0.01$ and ${ }^{\#} p<0.05$, by contrast with control group.

\subsubsection{Effect of CCSP-2 on 24-h Urine Protein}

Twenty-four-hour urine protein, commonly used to monitor kidney function, is considered as the gold standard for quantifying albuminuria. As can be found from Figure $4 \mathrm{~b}$, under physiological conditions, urine protein content was very low, and it rose sharply when the kidney was damaged by the intraperitoneal injection of LPS. After the administration of CCSP-2, $24 \mathrm{~h}$ urine protein decreased significantly, compared with the LPS group $(p<0.01)$ in a dose-dependent manner, indicating that CCSP-2 can improve renal function in LPS-induced septic AKI mice. 


\subsubsection{Effect of CCSP-2 on BUN and SCr Levels}

BUN and $\mathrm{SCr}$ are the end products of protein- and nitrogen-containing organic metabolism, respectively, and are commonly used clinical indicators of renal function. Figure 4c,d exhibit the effect of CCSP-2 on BUN and SCr levels in LPS-induced septic AKI mice. There was a remarkable difference in BUN and SCr levels between the LPS group and the control group $(p<0.01)$, showing that LPS treatment caused kidney damage in mice. The BUN and SCr levels in the CCSP-2-treated groups were notably lower than that of the LPS group $(p<0.01)$, dose-dependently.

\subsubsection{Effect of CCSP-2 on Serum Cytokine Levels}

The effect of CCSP- 2 on serum IL-1 $\beta$, IL- 6 , and TNF- $\alpha$ in the LPS-induced septic AKI mice were determined by ELISA, as displayed in Figure 5. LPS markedly boosted the serum IL-1 $\beta$, IL-6, and TNF- $\alpha$ levels, as compared with the control group $(p<0.01)$, signifying that the intraperitoneal injection of LPS caused an inflammatory response in mice; the administration of CCSP- 2 remarkably inhibited the expression of IL-1 $\beta$, IL-6, and TNF- $\alpha$ $(p<0.01)$, implying that CCSP-2 exerted a protective effect against LPS-induced septic AKI in mice through anti-inflammatory activity.

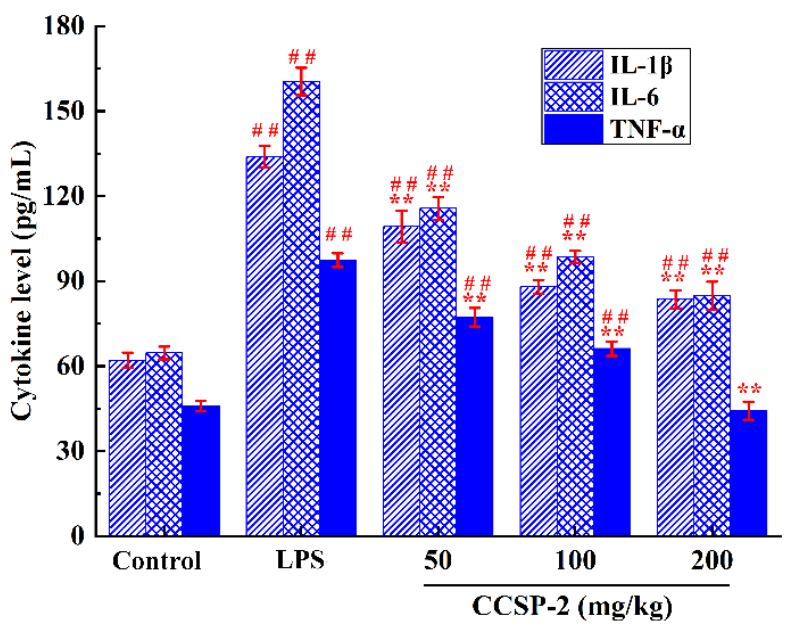

Figure 5. Effect of CCSP-2 on serum TNF- $\alpha$, IL-1 $\beta$, and IL-6 levels in LPS-induced septic AKI mice. Results are represented as means $\pm \mathrm{SD}(n=8) .{ }^{* *} p<0.01$, by contrast with the LPS group; ${ }^{\# \#} p<0.01$, by contrast with the control group.

3.6.5. Effect of CCSP-2 on Kidney Antioxidase Activities and Oxidative Damage Product Levels

Figure 6a displays the effect of CCSP-2 on the antioxidase activity of renal tissue in the LPS-induced septic AKI mice. The activities of T-SOD, CAT, and GSH-Px in the LPS-treated mice were remarkably lower than those of the control group $(p<0.01)$, indicating that LPS caused damage to the antioxidase system of renal tissue. The administration of CCSP-2 resulted in a significant increase in the antioxidase activities by comparison with the model control ( $p<0.05$ or $p<0.01$ ), suggesting that CCSP-2 could modulate the antioxidase system in the LPS-induced septic AKI mice.

As can be seen from Figure 6b, compared with the control group, the MDA and PCG levels of renal tissue in the LPS-treated mice were remarkably increased $(p<0.01)$, hinting that LPS led to oxidative damage of lipids and proteins. The MDA and PCG levels in the low-, medium-, and high-dose CCSP-2 groups were notably reduced $(p<0.05$ or $p<0.01)$, suggesting that CCSP-2 could alleviate the LPS-induced oxidative damage of renal tissue. 

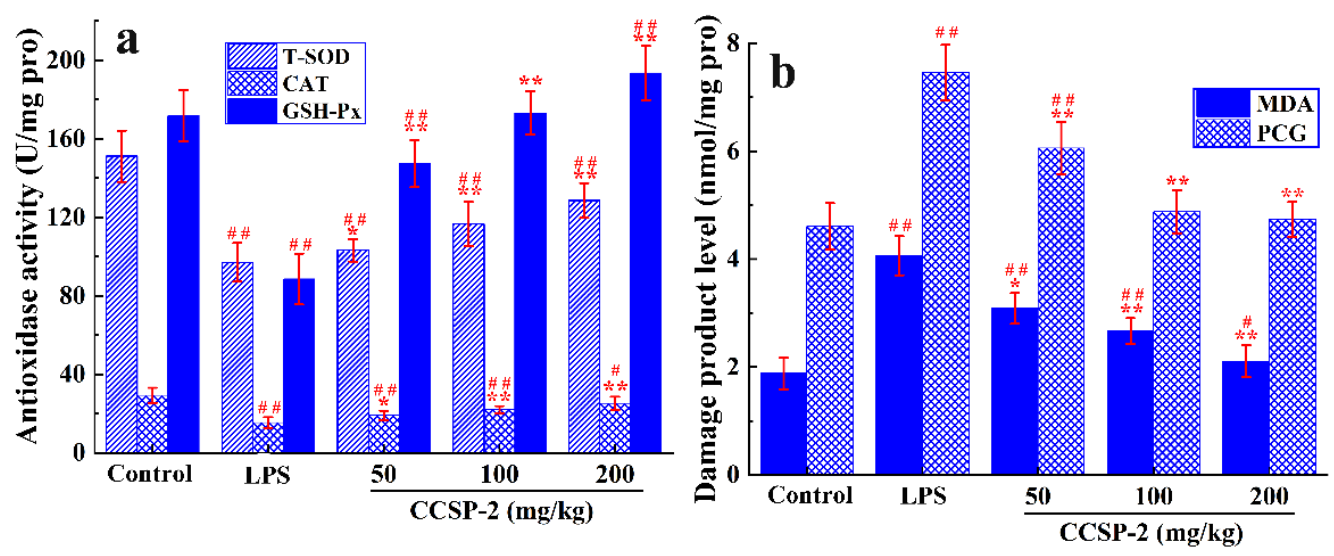

Figure 6. Effect of CCSP-2 on antioxidase activity (a) and oxidative damage product level (b) of kidney tissue in LPS-induced septic AKI mice. Results are expressed as means $\pm \operatorname{SD}(n=8) .{ }^{*} p<0.05$ and ${ }^{* *} p<0.01$, compared with the LPS group. ${ }^{\#} p<0.05$ and ${ }^{\# \#} p<0.01$, compared with the control group.

\section{Discussion}

The ethanol-ammonium sulfate ATPS is a time-saving, energy-saving, high-yield, and easy to scale-up technique that has been applied in the preparation of natural active polysaccharides. Cao et al. reported that the optimal microwave-assisted ATPE parameters for extraction of Sargassum pallidum polysaccharides were indicated as below: an ethanol concentration of $21.0 \%$, an ammonium sulfate concentration of $22.0 \%$, a liquid-to-material ratio of $60 \mathrm{~mL} / \mathrm{g}$, a microwave power of $830 \mathrm{~W}$, an extraction temperature of $95^{\circ} \mathrm{C}$, and an extraction time of $15 \mathrm{~min}$ [44]. Wang and Liu reported that the optimum conditions of microwave-assisted ATPS for Notopterygium franchetii polysaccharides were indicated as below: an ethanol concentration of $32 \%$, an ammonium sulfate concentration of $24 \%$, and an extraction time of $15 \mathrm{~min}$ [18]. The optimum process parameters obtained by different researchers vary greatly, which may be related to the types of raw materials, the size of raw materials, the types of polysaccharides, and other factors. In this study, HWE and ATPE were compared in terms of extraction time, polysaccharide yield, and product purity. The results show that ATPE is more applicable for the extraction of CCSPs due to its time-saving, high-yield, and high-purity qualities. Studies have shown that the physicochemical properties and biological activity of polysaccharides can be affected by different extraction methods [45-48]. Whether the different extraction methods have an impact on the physicochemical properties, structure, and biological activity of CCSPs remains to be further studied.

It is commonly required to combine two or more assays to evaluate the antioxidant activity of tested substances. In this study, the antioxidant activities of CCSP-1, CCSP-2, and CCSP-3 were assessed via their DPPH radical scavenging ability, hydroxyl radical scavenging ability, reducing power, and chelating ability against ferrous ions. DPPH radical scavenging ability is one of the most ordinarily used methods for the evaluation of antioxidant potential. When DPPH radicals are scavenged by antioxidants, the absorbance of DPPH solution decreases, so it can be employed to determine the antioxidant capacity [49]. The antioxidant capacities of the test samples are closely related to their reducing ability. The stronger the reducing power of the samples, the stronger their antioxidant activity [50]. Hydroxyl radicals, currently considered to be the most toxic and harmful reactive oxygen species (ROS), can attack a variety of biomolecules through electron transfer, addition, and dehydrogenation, resulting in oxidative damage to proteins, nucleic acids, and lipids [51]. Ferrous ions can catalyze Fenton's reaction in organisms to cause lipid peroxidation and generate hydroxyl radicals. The chelating ability against ferrous ions is also commonly used to evaluate antioxidant activity [52]. 
Our results showed that CCSP-1, CCSP-2, and CCSP-3 exhibited potent antioxidant activities in the above four assays, among which CCSP-2 had the strongest antioxidant capacity. The strong DPPH radical scavenging activity may be ascribed to the hydroxyl and carboxyl groups in samples, which can donate protons to reduce DPPH radicals [53]. Uronic acid and carboxyl groups, which could block Fenton's reaction by chelating ferrous ions and thereby inhibit the generation of hydroxyl radicals, might be partly in charge of the strong hydroxyl radical scavenging activity and chelating ability against ferrous ions [54]. The relationship between the molecular weight and the antioxidant capacity of polysaccharides has not been clearly elucidated. Rozi et al. demonstrated that the free radical scavenging ability of a Fritillaria pallidiflora polysaccharide fraction with lower molecular weight is higher than that of a fraction with a higher molecular weight [55]. Conversely, Su and Li [56] reported that the molecular weight was significantly positively relevant to scavenging activity against DPPH, superoxide, and hydroxyl radicals. However, no correlation between the antioxidant activity and molecular weight of polysaccharides (data not shown) was found in our research, which was not in agreement with previous studies. A possible explanation for this discrepancy might be that the antioxidant activity of polysaccharides is affected not only by molecular weight but also by monosaccharide composition, molecular conformation, and other factors. Additionally, it could conceivably be hypothesized that the correlation between molecular weight and antioxidant activity could be observed only when the molecular weight is within a certain range.

An animal model of septic AKI plays an important role in understanding its pathogenesis and early diagnostic treatment. Currently, there are three commonly used methods to establish septic AKI models: LPS injection, the infusion of exogenous bacteria, and surgery to change an animal's endogenous protective barrier, such as cecal ligation and puncture [57]. LPS, as the outer layer of the cell wall of Gram-negative bacteria, has been identified as the leading cause of septic AKI [58]. In this study the intraperitoneal injection of LPS into mice was used to establish a septic AKI model. After the injection of LPS, the $24 \mathrm{~h}$ urine protein, BUN, SCr, IL-1 $\beta$, IL-6, and TNF- $\alpha$ levels increased significantly, which proved the effectiveness of the septic AKI model.

Proinflammatory cytokines, such as IL-1 $\beta$, IL-6, and TNF- $\alpha$, play an important role in the pathological process of renal injury [59]. TNF-a and IL-6 are closely associated with the pathological changes of renal tubules. IL-1 $\beta$ also plays an important role in the inflammatory pathology and damage of renal tissue. The inhibition of these proinflammatory cytokines can alleviate LPS-induced septic AKI [60,61]. This study showed that CCSP-2 can inhibit the release of serum IL-1 $\beta$, IL-6, and TNF- $\alpha$ in LPS-induced septic AKI mice, suggesting that CCSP-2 exerted its protective effect on LPS-induced septic AKI by downregulating the expression of proinflammatory cytokines. It is reported that a polysaccharide from Sanguisorba officinalis, namely, RSP-3, exhibited significant anti-inflammatory activity in LPS-induced AKI mice by decreasing TNF- $\alpha$ and IL-6 levels [31]. Another study showed that Lycium barbarum polysaccharides could lead to a significant decrease in the serum levels of IL-1 $\beta$, IL-6, IL-8, NF- $k B$, and TNF- $\alpha$ in LPS-induced septic AKI rats [23]. Our results are in agreement with the above studies.

A large number of studies have shown that the production of reactive oxygen species (ROS) and the imbalance of the antioxidant system are important mechanisms for the occurrence and progression of septic AKI. Neutrophil oxidative burst, arachidonic acid metabolism, and other pathways release a large amount of ROS during sepsis, which can cause oxidative damage to biological molecules such as lipids and proteins [62]. Alleviating oxidative stress exclusively cannot effectively prevent sepsis AKI; however, the supplementation of antioxidants in a comprehensive treatment might be a considerable strategy. T-SOD, CAT, and GSH-Px are important components of the antioxidant enzyme system. The activity of antioxidant enzymes reflects the degree of oxidative stress of the tissues or organs. MDA and PCG are critical indicators with which to determine whether lipids and proteins are oxidized by ROS, respectively. This study showed that LPS exposure significantly reduced T-SOD, CAT, and GSH-Px activities in addition to increasing 
MDA and PCG levels, while CCSP-2 treatment abolished these effects, indicating that CCSP-2 can improve the antioxidant capacity of LPS-induced septic AKI mice. Recently, Echinacea polysaccharide have been demonstrated to decrease ROS, malondialdehyde, and oxidized glutathione levels as well as increase SOD, CAT, and glutathione reductase while decreasing glutathione activity [32]. Astragalus polysaccharide could have increased T-SOD and GSH-Px activities as well as inhibited oxidative stress marker 3-NT expression in cisplatin-induced AKI mice [33]. Our results are consistent with these studies.

Our results preliminarily elucidated the mechanisms of CCSP-2 against LPS-induced septic AKI in mice. The underlying mechanisms are attributed to the inhibition of oxidative stress and inflammatory responses. Nevertheless, further studies should be performed to explore the signaling pathways involved in the anti-inflammatory and antioxidant activities of CCSP-2.

\section{Conclusions}

ATPE is a time-saving, energy-saving, high-yield, and high-purity method for the extraction of CCSPs. The optimal parameters of ATPE for CCSPs were as follows: an extraction temperature of $61{ }^{\circ} \mathrm{C}$, an ammonium sulfate concentration of $18 \%$, an ethanol concentration of $40 \%$, a liquid-to-material ratio of $33 \mathrm{~mL} / \mathrm{g}$, and an extraction time of $60 \mathrm{~min}$. The CCSPs yield was $6.96 \pm 0.11 \%(n=3)$, which was in accordance with the predicted yield $(6.92 \%)$. CCSP-2 showed strong scavenging activities against DPPH radicals and hydroxyl radicals, reducing power, and ferrous-ion-chelating ability.

CCSP-2 can attenuate LPS-induced renal edema, inhibit $24 \mathrm{~h}$ urine protein, BUN and $\mathrm{SCr}$ levels, downregulate the expression of proinflammatory cytokines, modulate the antioxidase system, and alleviate LPS-induced oxidative damage. These results hint that CCSP-2 exhibits the renal protective effect against LPS-induced septic AKI in mice via anti-inflammatory and antioxidant pathways. TOP-2 might be exploited as a promising natural antioxidant and anti-inflammatory supplement for the adjuvant therapy of LPSinduced septic AKI in addition to other diseases induced by inflammatory responses and oxidative stress.

Author Contributions: Conceptualization, Y.Z. and A.C.; methodology, Y.Z.; software, S.L.; validation, S.L. and C.L.; formal analysis, Y.Z.; investigation, S.L. and C.L.; resources, A.C.; data curation, Y.S.; writing-original draft preparation, Y.Z.; writing-review and editing, A.C.; visualization, Y.Z.; supervision, A.C.; project administration, Y.S.; funding acquisition, A.C. All authors have read and agreed to the published version of the manuscript.

Funding: This research was funded by the Xuzhou Science and Technology Project, grant number kc21119.

Institutional Review Board Statement: The animal study protocol was approved by the Ethics Committee of Animal Care and Use Committee of Xuzhou University of Technology (protocol code XUTFEC 2020-002 and date of approval 5 January 2020).

Informed Consent Statement: Not applicable.

Data Availability Statement: Not applicable.

Conflicts of Interest: The authors declare no conflict of interest.

\section{References}

1. Chu, Z.B.; Chang, J.; Zhu, Y.; Sun, X. Chemical constituents of Cordyceps cicadae. Nat. Prod. Commun. 2015, 10, 2145-2146. [CrossRef] [PubMed]

2. Nxumalo, W.; Elateeq, A.A.; Sun, Y.F. Can Cordyceps cicadae be used as an alternative to Cordyceps militaris and Cordyceps sinensis?-A review. J. Ethnopharmacol. 2020, 257, 112879. [CrossRef] [PubMed]

3. Yang, N.N.; Jiang, N.; Ma, Q.Y.; Kong, F.D.; Xie, Q.Y.; Zhou, L.M.; Yu, Z.F.; Zhao, Y.X. Chemical study of the strain Cordyceps spp. from cell fusion between Cordyceps militaris and Cordyceps cicadae. J. Asian Nat. Prod. Res. 2019, 21, 449-455. [CrossRef] [PubMed]

4. Zhu, Y.L.; Yu, X.F.; Ge, Q.; Li, J.; Wang, D.J.; Wei, Y.; Ouyang, Z. Antioxidant and anti-aging activities of polysaccharides from Cordyceps cicadae. Int. J. Biol. Macromol. 2020, 157, 394-400. [CrossRef] 
5. Yang, C.H.; Su, C.H.; Liu, S.C.; Ng, L.T. Isolation, anti-inflammatory activity and physicochemical properties of bioactive polysaccharides from fruiting bodies of cultivated Cordyceps cicadae (Ascomycetes). Int. J. Med. Mushrooms 2019, 21, 995-1006. [CrossRef]

6. Xu, Z.; Lin, R.; Hou, X.; Wu, J.; Zhao, W.; Ma, H.; Fan, Z.; Li, S.; Zhu, Y.; Zhang, D. Immunomodulatory mechanism of a purified polysaccharide isolated from Isaria cicadae Miquel on RAW264.7 cells via activating TLR4-MAPK-NF-kappaB signaling pathway. Int. J. Biol. Macromol. 2020, 164, 4329-4338. [CrossRef]

7. Xu, Z.; Yan, X.; Song, Z.; Li, W.; Zhao, W.; Ma, H.; Du, J.; Li, S.; Zhang, D. Two heteropolysaccharides from Isaria cicadae Miquel differ in composition and potentially immunomodulatory activity. Int. J. Biol. Macromol. 2018, 117, 610-616. [CrossRef]

8. Zhang, Q.; Olatunji, O.J.; Chen, H.; Tola, A.J.; Oluwaniyi, O.O. Evaluation of the Anti-Diabetic Activity of Polysaccharide from Cordyceps cicadae in Experimental Diabetic Rats. Chem. Amp. Biodivers. 2018, 15, e1800219. [CrossRef]

9. Zhang, Y.; Wu, Y.T.; Zheng, W.; Han, X.X.; Jiang, Y.H.; Hu, P.L.; Tang, Z.X.; Shi, L.E. The antibacterial activity and antibacterial mechanism of a polysaccharide from Cordyceps cicadae. J. Funct. Foods 2017, 38, 273-279. [CrossRef]

10. Olatunji, O.J.; Feng, Y.; Olatunji, O.O.; Tang, J.; Wei, Y.; Ouyang, Z.; Su, Z.L. Polysaccharides purified from Cordyceps cicadae protects PC12 cells against glutamate-induced oxidative damage. Carbohydr. Polym. 2016, 153, 187-195. [CrossRef]

11. Yang, J.; Dong, H.; Wang, Y.; Jiang, Y.; Zhang, W.; Lu, Y.; Chen, Y.; Chen, L. Cordyceps cicadae polysaccharides ameliorated renal interstitial fibrosis in diabetic nephropathy rats by repressing inflammation and modulating gut microbiota dysbiosis. Int. J. Biol. Macromol. 2020, 163, 442-456. [CrossRef] [PubMed]

12. Sun, Y.F.; Wink, M.; Wang, P.; Lu, H.F.; Zhao, H.X.; Liu, H.T.; Wang, S.X.; Sun, Y.; Liang, Z.S. Biological characteristics, bioactive components and antineoplastic properties of sporoderm-broken spores from wild Cordyceps cicadae. Phytomedicine 2017, 36 , 217-228. [CrossRef] [PubMed]

13. Chong, K.Y.; Brooks, M.S.-L. Effects of recycling on the aqueous two-phase extraction of bioactives from haskap leaves. Sep. Purif. Technol. 2021, 255, 117755. [CrossRef]

14. Yau, Y.K.; Ooi, C.W.; Ng, E.-P.; Lan, J.C.-W.; Ling, T.C.; Show, P.L. Current applications of different type of aqueous two-phase systems. Bioresour. Bioprocess. 2015, 2, 49. [CrossRef]

15. Huang, Y.X.; Wu, X.H.; Zhou, S.Y.; Lin, Y.Y.; Zhang, W.; Fu, C.J.; Luo, L.C.; Wang, K.; Xie, X.J.; Fan, H.J. Biphasic extraction of different polysaccharides from Radix Sophorae Tonkinensis by microwave-assisted aqueous two-phase extraction: Process optimization, structural characterization and mechanism exploration. Sep. Purif. Technol. 2018, 207, 187-198. [CrossRef]

16. Lin, Y.Y.; Zeng, H.Y.; Wang, K.; Lin, H.; Li, P.F.; Huang, Y.X.; Zhou, S.Y.; Zhang, W.; Chen, C.; Fan, H.J. Microwave-assisted aqueous two-phase extraction of diverse polysaccharides from Lentinus edodes: Process optimization, structure characterization and antioxidant activity. Int. J. Biol. Macromol. 2019, 136, 305-315. [CrossRef]

17. Zhu, L.N.; Lu, Y.; Sun, Z.; Han, J.; Tan, Z.J. The application of an aqueous two-phase system combined with ultrasonic cell disruption extraction and HPLC in the simultaneous separation and analysis of solanine and Solanum nigrum polysaccharide from Solanum nigrum unripe fruit. Food Chem. 2020, 304, 125383. [CrossRef]

18. Wang, W.; Liu, J. Efficient extraction, antioxidant activities and anti-inflammation of polysaccharides from Notopterygium franchetii Boiss. Carbohydr. Polym. 2020, 248, 116783. [CrossRef]

19. Zhao, M.M.; Bai, J.W.; Bu, X.Y.; Tang, Y.; Han, W.Q.; Li, D.L.; Wang, L.B.; Yang, Y.; Xu, Y.Q. Microwave-assisted aqueous two-phase extraction of phenolic compounds from Ribes nigrum L. and its antibacterial effect on foodborne pathogens. Food Control 2021, 119, 107449. [CrossRef]

20. Enriquez-Ochoa, D.; Sánchez-Trasviña, C.; Hernández-Sedas, B.; Mayolo-Deloisa, K.; Zavala, J.; Rito-Palomares, M.; ValdezGarcía, J.E. Aqueous two-phase extraction of phenolic compounds from Sedum dendroideum with antioxidant activity and anti-proliferative properties against breast cancer cells. Sep. Purif. Technol. 2020, 251, 117341. [CrossRef]

21. Odabaş, H.I..; Koca, I. Simultaneous separation and preliminary purification of anthocyanins from Rosa pimpinellifolia L. fruits by microwave assisted aqueous two-phase extraction. Food Bioprod. Processing 2021, 125, 170-180. [CrossRef]

22. Prowle, J.R.; Bellomo, R. Sepsis-associated acute kidney injury: Macrohemodynamic and microhemodynamic alterations in the renal circulation. Semin. Nephrol. 2015, 35, 64-74. [CrossRef] [PubMed]

23. Wu, Q.; Liu, L.T.; Wang, X.Y.; Lang, Z.F.; Meng, X.H.; Guo, S.F.; Yan, B.; Zhan, T.; Zheng, H.Z.; Wang, H.W. Lycium barbarum polysaccharides attenuate kidney injury in septic rats by regulating Keap1-Nrf2/ARE pathway. Life Sci. 2020, 242, 117240. [CrossRef] [PubMed]

24. Liu, M.; Li, S.S.; Wang, X.X.; Zhu, Y.F.; Zhang, J.J.; Liu, H.; Jia, L. Characterization, anti-oxidation and anti-inflammation of polysaccharides by Hypsizygus marmoreus against LPS-induced toxicity on lung. Int. J. Biol. Macromol. 2018, 111, 121-128. [CrossRef]

25. Xu, X.Y.; Rui, S.Z.; Chen, C.; Zhang, G.C.; Li, Z.; Wang, J.H.; Luo, Y.P.; Zhu, H.P.; Ma, X.M. Protective effects of astragalus polysaccharide nanoparticles on septic cardiac dysfunction through inhibition of TLR4/NF-kappa B signaling pathway. Int. J. Biol. Macromol. 2020, 153, 977-985. [CrossRef]

26. Feng, Y.C.; Weng, H.B.; Ling, L.J.; Zeng, T.; Zhang, Y.Y.; Chen, D.F.; Li, H. Modulating the gut microbiota and inflammation is involved in the effect of Bupleurum polysaccharides against diabetic nephropathy in mice. Int. J. Biol. Macromol. 2019, 132, 1001-1011. [CrossRef] 
27. Chen, D.D.; Xu, R.; Zhou, J.Y.; Chen, J.Q.; Wang, L.; Liu, X.S.; Liang, C.L.; Liu, B.H.; Lu, R.R.; Wu, J.B.; et al. Cordyceps militaris polysaccharides exerted protective effects on diabetic nephropathy in mice via regulation of autophagy. Food Funct. 2019, 10, 5102-5114. [CrossRef]

28. Han, C.Y.; Sun, T.T.; Liu, Y.W.; Fan, G.T.; Zhang, W.J.; Liu, C.Y. Protective effect of Polygonatum sibiricum polysaccharides on gentamicin-induced acute kidney injury in rats via inhibiting p38 MAPK/ATF2 pathway. Int. J. Biol. Macromol. 2020, 151, 595-601. [CrossRef]

29. Ma, Q.; Xu, Y.; Tang, L.M.; Yang, X.Q.; Chen, Z.J.; Wei, Y.H.; Shao, X.H.; Shao, X.G.; Xin, Z.X.; Cai, B.; et al. Astragalus polysaccharide attenuates cisplatin-induced acute kidney injury by suppressing oxidative damage and mitochondrial dysfunction. Biomed Res. Int. 2020, 2020, 2851349. [CrossRef]

30. Su, D.Y.; Li, S.; Zhang, W.; Wang, J.; Wang, J.J.; Lv, M.H. Structural elucidation of a polysaccharide from Lonicera japonica flowers, and its neuroprotective effect on cerebral ischemia-reperfusion injury in rat. Int. J. Biol. Macromol. 2017, 99, 350-357. [CrossRef]

31. Zhao, W.; Zeng, X.; Meng, F.; Bi, X.; Xu, D.; Chen, X.; Li, Q.; Han, Y. Structural characterization and in vitro-in vivo evaluation of effect of a polysaccharide from Sanguisorba officinalis on acute kidney injury. Food Funct. 2019, 10, 7142-7151. [CrossRef] [PubMed]

32. Shi, Q.; Lang, W.; Wang, S.; Li, G.; Bai, X.; Yan, X.; Zhang, H. Echinacea polysaccharide attenuates lipopolysaccharide-induced acute kidney injury via inhibiting inflammation, oxidative stress and the MAPK signaling pathway. Int. J. Mol. Med. 2021, 47, 243-255. [CrossRef] [PubMed]

33. Sun, J.; Wei, S.; Zhang, Y.; Li, J. Protective Effects of Astragalus Polysaccharide on Sepsis-Induced Acute Kidney Injury. Anal. Cell. Pathol. 2021, 2021, 7178253. [CrossRef] [PubMed]

34. Huang, Y.S.; Wang, X.; Feng, Z.; Cui, H.; Zhu, Z.; Xia, C.; Han, X.; Liu, W.J.; Liu, Y.N. Cordyceps cicadae Prevents Renal Tubular Epithelial Cell Apoptosis by Regulating the SIRT1/p53 Pathway in Hypertensive Renal Injury. Evid.-Based Complement. Altern. Med. 2020, 2020, 7202519. [CrossRef] [PubMed]

35. Deng, J.; Jiang, W.; Chen, C.; Lee, L.; Li, P.; Huang, W.; Liao, J.; Chen, H.; Huang, S.; Huang, G. Cordyceps cicadae mycelia ameliorate cisplatin-induced acute kidney injury by suppressing the TLR4/NF- $\kappa$ B/MAPK and activating the HO-1/Nrf2 and Sirt-1/AMPK pathways in mice. Oxid. Med. Cell. Longev. 2020, 2020, 7912763. [CrossRef]

36. Dubois, M.; Gilles, K.A.; Hamilton, J.K.; Rebers, P.A.; Smith, F.J.A.C. Colorimetric method for determination of sugars and related substances. Anal. Chem. 1956, 28, 350-356. [CrossRef]

37. Zheng, Y.; Wang, W.D.; Li, Y. Antitumor and immunomodulatory activity of polysaccharide isolated from Trametes orientalis Carbohydr. Polym. 2015, 131, 248-254. [CrossRef]

38. Wu, H.; Chen, H.; Shiau, C. Free amino acids and peptides as related to antioxidant properties in protein hydrolysates of mackerel (Scomber austriasicus). Food Res. Int. 2003, 36, 949-957. [CrossRef]

39. Yen, G.C.; Hsieh, P.P. Antioxidative activity and scavenging effects on active oxygen of xylose-lysine maillard reaction products. $J$ Sci. Food Agric. 1995, 67, 415-420. [CrossRef]

40. Oraiza, M. Studies on product of browning reaction prepared from glucosamine. Jpn. J. Nutr. 1986, 44, 307-315.

41. Decker, E.A.; Welch, B. Role of ferritin as a lipid oxidation catalyst in muscle food. J. Agric. Food Chem. 1990, 38, 674-677. [CrossRef]

42. Li, X.; Chen, H.; Zha, X.; Chen, S.; Pan, L.; Li, Q.; Luo, J. Prevention and possible mechanism of a purified Laminaria japonica polysaccharide on adriamycin-induced acute kidney injury in mice. Int. J. Biol. Macromol. 2020, 148, 591-600. [CrossRef] [PubMed]

43. Rübig, E.; Stypmann, J.; Van Slyke, P.; Dumont, D.J.; Spieker, T.; Buscher, K.; Reuter, S.; Goerge, T.; Pavenstädt, H.; Kümpers, P. The synthetic Tie2 agonist peptide vasculotide protects renal vascular barrier function in experimental acute kidney injury. Sci. Rep. 2016, 6, 22111. [CrossRef] [PubMed]

44. Cao, C.; Huang, Q.; Zhang, B.; Li, C.; Fu, X. Physicochemical characterization and in vitro hypoglycemic activities of polysaccharides from Sargassum pallidum by microwave-assisted aqueous two-phase extraction. Int. J. Biol. Macromol. 2018, 109, 357-368 [CrossRef]

45. Chen, G.; Fang, C.; Ran, C.; Tan, Y.; Yu, Q.; Kan, J. Comparison of different extraction methods for polysaccharides from bamboo shoots (Chimonobambusa quadrangularis) processing by-products. Int. J. Biol. Macromol. 2019, 130, 903-914. [CrossRef]

46. He, L.; Yan, X.; Liang, J.; Li, S.; He, H.; Xiong, Q.; Lai, X.; Hou, S.; Huang, S. Comparison of different extraction methods for polysaccharides from Dendrobium officinale stem. Carbohydr. Polym. 2018, 198, 101-108. [CrossRef]

47. Chen, S.; Shang, H.; Yang, J.; Li, R.; Wu, H. Effects of different extraction techniques on physicochemical properties and activities of polysaccharides from comfrey (Symphytum officinale L.) root. Ind. Crops Prod. 2018, 121, 18-25. [CrossRef]

48. Chen, G.; Chen, X.; Yang, B.; Yu, Q.; Wei, X.; Ding, Y.; Kan, J. New insight into bamboo shoot (Chimonobambusa quadrangularis) polysaccharides: Impact of extraction processes on its prebiotic activity. Food Hydrocoll. 2019, 95, 367-377. [CrossRef]

49. Chen, G.T.; Ma, X.M.; Liu, S.T.; Liao, Y.L.; Zhao, G.Q. Isolation, purification and antioxidant activities of polysaccharides from Grifola frondosa. Carbohydr. Polym. 2012, 89, 61-66. [CrossRef]

50. Fan, L.; Li, J.; Deng, K.; Ai, L. Effects of drying methods on the antioxidant activities of polysaccharides extracted from Ganoderma lucidum. Carbohydr. Polym. 2012, 87, 1849-1854. [CrossRef]

51. Wu, G.H.; Hu, T.; Li, Z.Y.; Huang, Z.L.; Jiang, J.G. In vitro antioxidant activities of the polysaccharides from Pleurotus tuber-regium (Fr.) Sing. Food Chem. 2014, 148, 351-356. [CrossRef] [PubMed] 
52. Chen, H.; Ju, Y.; Li, J.; Yu, M. Antioxidant activities of polysaccharides from Lentinus edodes and their significance for disease prevention. Int. J. Biol. Macromol. 2012, 50, 214-218. [CrossRef] [PubMed]

53. Mzoughi, Z.; Abdelhamid, A.; Rihouey, C.; Le Cerf, D.; Bouraoui, A.; Majdoub, H. Optimized extraction of pectin-like polysaccharide from Suaeda fruticosa leaves: Characterization, antioxidant, anti-inflammatory and analgesic activities. Carbohydr. Polym. 2018, 185, 127-137. [CrossRef] [PubMed]

54. Wang, Z.; Jia, S.; Cui, J.; Qu, J.; Yue, Y.; Sun, Q.; Zhang, H. Antioxidant activity of a polysaccharide produced by Chaetomium globosum CGMCC 6882. Int. J. Biol. Macromol. 2019, 141, 955-960. [CrossRef] [PubMed]

55. Rozi, P.; Abuduwaili, A.; Mutailifu, P.; Gao, Y.H.; Rakhmanberdieva, R.; Aisa, H.A.; Yili, A. Sequential extraction, characterization and antioxidant activity of polysaccharides from Fritillaria pallidiflora Schrenk. Int. J. Biol. Macromol. 2019, 131, 97-106. [CrossRef]

56. Su, Y.; Li, L. Structural characterization and antioxidant activity of polysaccharide from four auriculariales. Carbohydr. Polym. 2020, 229, 115407. [CrossRef]

57. Dejager, L.; Pinheiro, I.; Dejonckheere, E.; Libert, C. Cecal ligation and puncture: The gold standard model for polymicrobial sepsis? Trends Microbiol. 2011, 19, 198-208. [CrossRef]

58. Ramesh, G.; Reeves, W.B. TNF- $\alpha$ mediates chemokine and cytokine expression and renal injury in cisplatin nephrotoxicity. J. Clin. Investig. 2002, 110, 835-842. [CrossRef]

59. Akcay, A.; Nguyen, Q.; Edelstein, C.L. Mediators of Inflammation in Acute Kidney Injury. Mediat. Inflamm. 2009, $2009,137072$. [CrossRef]

60. Al-Harbi, N.O.; Nadeem, A.; Ahmad, S.F.; Alanazi, M.M.; Aldossari, A.A.; Alasmari, F. Amelioration of sepsis-induced acute kidney injury through inhibition of inflammatory cytokines and oxidative stress in dendritic cells and neutrophils respectively in mice: Role of spleen tyrosine kinase signaling. Biochimie 2019, 158, 102-110. [CrossRef]

61. Mir, S.M.; Ravuri, H.G.; Pradhan, R.K.; Narra, S.; Kumar, J.M.; Kuncha, M.; Kanjilal, S.; Sistla, R. Ferulic acid protects lipopolysaccharide-induced acute kidney injury by suppressing inflammatory events and upregulating antioxidant defenses in Balb/c mice. Biomed. Pharmacother. 2018, 100, 304-315. [CrossRef] [PubMed]

62. Barichello, T.; Fortunato, J.J.; Vitali, Â.M.; Feier, G.; Reinke, A.; Moreira, J.C.F.; Quevedo, J.; Dal-Pizzol, F. Oxidative variables in the rat brain after sepsis induced by cecal ligation and perforation. Crit. Care Med. 2006, 34, 886-889. [CrossRef] [PubMed] 